\title{
Study on the Current Application Condition and Development Situation of Social Media in Sports Industry
}

\author{
Yuan Zhang \\ Northwest University, Xian 710069, China
}

Keyword: Social media; Sports industry; Internet; New media; Sport field

\begin{abstract}
Goal: Since the 2019 Basketball world cup for males and 2022 Winter Olympics are going to be hold in China, we might have an intense period of major sporting events in the next 10 years. It can be deemed as a challenge and chance for sports industry of China. However, we have to further analyze how to promote the sports industry development, improve the sporty consumption habits, and broaden marketing channel based on social media in this internet era.

Result: The sports industry and social media are tied together, and the function of social media will be highlighted when the sporty information is being facilitated. Therefore, in the era when informationization is developing fast, we have to promote the development of social media.

Conclusion: The government should take advantage of the opportunity of internet to strengthen the idea of national fitness and healthy sport activities, invest money on sporty field, family activities so as to encourage the public to carry out sporty activities. In the meanwhile, we have to positively respond to the government policies, and adopt social media as a communication means to promote and attract people from various fields to improve the consumer awareness of the sporty field.
\end{abstract}

\section{Definition of Social Media in Modern Times}

Social media, separately speaking is socialization and media, which is the agency and carrier to disseminate information. If we want to better understand the idea of socialization we have to find a coordinated concept, which should be social media, building media, and TV media. Concerning the definition of social media, there are lots of studies from abroad and at home. To conclude, it can be summarized by goals, contents and methods: the goal is to carry out multiple communication; take public creation as contents and the method is the new public media based on internet. The concept of social media has existed for a long time, which is now being mentioned often because of the continuous development of modern internet time bringing with new hope. For example, BBS forum has existed for a long time, which is now receiving continuous focus, which cannot be separated from the development of internet technology.

The communication tool we use often is a kind of social media. The types of these medias are shown in Table 1.

From it, we can conclude taht the characteristics, which are participation, are open, communication, socialization and connection. These five parts are interdependent.

\section{The Application of Social media in Sporty Industry}

When you want to comment on the video of Rockets versus Spurs, when you follow Jianlian Yi on Weibo, when you locate yourself using the running app, they can all be considered as the combination of sporty industry with social media. The approaching of the internet era brought about the idea of netizen. Until June 2015, there have been 668 million netizens and there are 594 million people using mobile phones. From PC to mobile, netizens have gone through a key step of intelligent social connection. In addition, the number of social media is soaring and the application in sporty filed is diversified. In 2005, various portals began the blog business. During that time, the football commentator, Dong Luli and the basketball player Liu Weizheng began to write blog, which opened a new charter for the social media. What's more, with the emerge of video sharing, 
the broadcast of sporty events become a kind of recreation form for netizens and Youku, Iqiyi, Tudou began to sign contracts with sporty events and they broadcasted lots of sporty events abroad and at home. If we say the blog opened the new charter of social media, then the lunch of Sina helped the sporty filed go into a new era and a glittering array of official sporty organizations opened an account in Sina to carry out effective interactions with netizens and to enhance the market penetration. Furthermore, with the emergence of moments of wechat, the official wechat account also brought about new lives for the sporty field. Customers can follow the relevant sporty accounts based on their hobbies to get access to information anywhere

and anytime. What is worth mentioning is that when the chat becomes the main social media, the mobile customers

Table 1 Social media types distribution

\begin{tabular}{|l|l|l|l|}
\hline & Social media type & $\begin{array}{l}\text { Typical representative } \\
\text { abroad }\end{array}$ & $\begin{array}{l}\text { Typical representative at } \\
\text { home }\end{array}$ \\
\hline $\begin{array}{l}\text { Social } \\
\text { media } \\
\text { framewor } \\
\mathrm{k}\end{array}$ & Social network & Facebook & Kaixin, Renren \\
\hline \multirow{5}{*}{$\begin{array}{l}\text { Business Social } \\
\text { Service Networking }\end{array}$} & Linked IN & Wealink \\
\cline { 2 - 4 } & Weibo & Twitter & Sina Weibo, Tencent Weibo \\
\cline { 2 - 4 } & Video Sharing & YouTube & Youku, iqiyi \\
\cline { 2 - 4 } & Social commerce & Groupon & Meituan, Lashou \\
\cline { 2 - 4 } & Location service & Fourquare & Jiepang \\
\cline { 2 - 4 } & Instant message & MSN & QQ \\
\cline { 2 - 4 } & RSS subscription & Google RSS & Baidu Rss \\
\cline { 2 - 4 } & Consumption review & Yelp & Dianping \\
\cline { 2 - 4 } & Wikipedia & WIKI & Zhidao, Hudong \\
\hline & Questions/answers & Answers & Zhihu, Tianya \\
\hline Social bookmark & Delicious & QQ Bookmark \\
\hline Music/ book sharing & Flickr & Xiami \\
\hline Blog & Blogger & Sina Blog \\
\hline Forum & Zynga Boards & Mop, Baidu Tieba \\
\hline Social game & & Harm \\
\hline
\end{tabular}

also become the main force of sporty field. Please refer to the following table:

Table 2 Penetration rate of social media in various thresholds in 2014

\begin{tabular}{|c|c|c|c|}
\hline & Wechat & Sina & BBS \\
\hline Mobile & $74.8 \%$ & $18.4 \%$ & $8.9 \%$ \\
\hline Tablet & $5.2 \%$ & $4.8 \%$ & $3.8 \%$ \\
\hline PC & $9.3 \%$ & $15.9 \%$ & $15.1 \%$ \\
\hline
\end{tabular}


Sporty Organizations have Limited Knowledge of the Function of Social Media.The development of social media is fast and there are various media and each one has their own property and characteristics. Sporty organizations began to adopt social media to promote but they don't have a good knowledge of the core function and as a result lots of operations do not work. For example, the social media like Sina can create good interactions and every netizen can comment and forward it. As an official account, it is not responsible to reply because it aims to promote, the interaction is considered as its subsidiary and only when we clear this point can we effectively work.

Sporty Organizations in Social Media are Less Active.It is not enough to only register an account and give a voice occasionally for sporty organizations to promote based on social media. The characteristics of social media is participation, being open, communication, socialization and connection and it should focus on the communication contents and frequently promote it. Wechat, as a modern social media has lots of official organizations but the event is not hold everyday so these accounts do not update every day. Only when the event is approaching, they will update so they do not give voice often and are not able to attract the attention of customers, which will inevitably reduce the effect.

\section{The Promotions Effect on Sporty Field of Social Media}

Improve the Consumption Awareness of Sporty Field. Since the development of social media, the sporty filed is gradually improving the scale and capital, and we can hear positive effects on policy support and sport philosophy. In 2012 , the sporty industry occupies $0.6 \%$ of the GDP, which is way lower than the average $2.0 \%$ and this means the social media has been improved a lot. In terms of sports industry structure, the consumption awareness of Chinese people is not as good as American people, the consumption on sporty goods in American is $80 \%$, which is only $30 \%$ in China.

The emergence of social media helps more and more pay attention to healthy sports and lots of sports service industries, including fitness entertainment, competitive sports appeared. In addition, the sporty requirement of the public becomes diversified. According to the research carried out among people between 20-69 years old in 2014, we found out that half of them did physical fitness, which increased by $1.5 \%$.

\section{Expand Consumption Channel of the Sporty Channel}

The emergence of social media changed the consumption mode of people and people can buy both physical products and virtual items or even service online. What's more, with the popularization of smart phones, the mobile portal becomes the marketing field of various

Table 3 Diversity evolution of sports demand of public

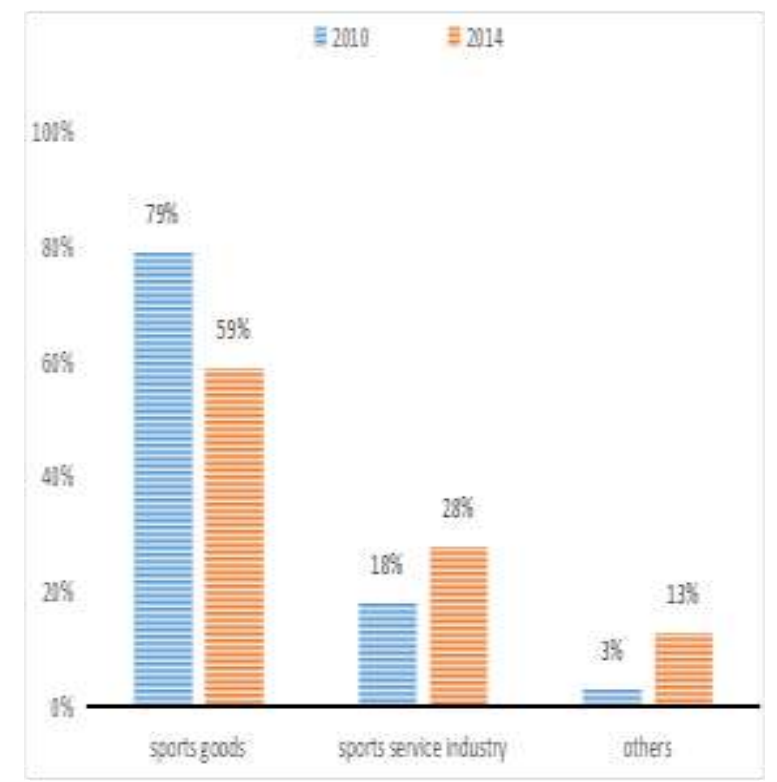


Merchants. The sporty industry develops along with this trend and got promoted via we chat and Sina etc, which can help people have a better knowledge of the sporty goods and they will finally become online or offline sales. Forums like BBC provides customers the right to comment on sporty products, which affect the consumers and help the manufactures to understand whether the products are proper or not so they will quickly respond. In addition, the sporty products manufacturers can carry out questionnaires via forum websites and at the same time get a good knowledge of market demand and improve the production efficiency based on demand and supply. Generally speaking, the social media is able to expand the consumption channel for sporty products, which can bring about positive effect on the development of sporty industry.

Improve the Effect of Sporty Stars. Even though sporty stars are not as popular as singers, they have good skills and people think it is difficult to connect with them and they can only see them in sporty events. The emergence of social media broke this idea because the public can get access to them. For example, Olympic gold medalist Li Xiaopeng is still working on sport after retiring and he will constantly post the pictures of his son and daughter, and he will also talk about the enjoyment of sport; Sun Yang, a famous swimmer is a big smiling boy in real life, all his pictures show his smile and he is good at running, swimming as well as hiking. They have lots of followers in Sina and lots of fans begin to participate in sports under the influence of them. In addition, there are lots of sporty stars like Li Xiaopeng and Sun Yang and their emergence is inevitable in the context of social media. They will carry out close interactions with fans via wechat, weibo and ProCamera and their speech is more interesting than normal teaching because they are influential and people like to hear from them.

Improve the Management of Current Sporty Organizations. The management of a company does not only depend on leaders but the mutual force of all employees. For a industry, it has more extensive aspects and people from all industries are responsible to make progress. The public plays a role of supervision in sporty field and the emergence of social media makes this function easier. For example, in basketball and football events, the public will give a relatively fair judgment if there is a fight between players. What's more, the public is able to restore the event when they explain in portals. For sporty enterprises, they are able to find out the management problems after a summary. The internet connection is fast and people can comment freely, which is beneficial to exposure and attract attention. Based on this, people can clear their mind and have a deeper understanding on the sport industry.

Conclusion: Under the influence of the network era, the sport industry in China is experiencing a new reform and the industrial structure is also having new changes. The concept of social media has existed for a long time, which is getting new opportunities because of the internet development. Social media is beneficial to the revitalization of industry and can facilitate the sport consumption. We have to focus on four perspectives: how to improve people's consumption awareness of sporty goods, expand the consumption channel, improve the effect of sport stars and enhance the management skill of sport organizations so as to stimulate the development of sporty industry in China.

\section{References}

[1] S. Reed, "American sports writers' social media use and its influence on professionalism," Journalism Practice, 2013, 7(5):555-571

[2] B Zheng,W Wang,G Jiang,K Wang,X Mei, Research status and application prospects of manufacturing technology for micro-nano surface structures with low reflectivity, Proceedings of the Institution of Mechanical Engineers, 2014, 229(11):953-965

[3] Anonymous. Youth Empowerment Through Sports Toward Health and Social Development Forum[J]. Research Quarterly for Exercise and Sport,2016,87S2:. 
[4] N O'Reilly,IE Berger,T Hernandez,MM Parent,B Seguin, Understanding adolescent sport participation through online social media[J]. Sport, Business and Management, 2012, 2(1):6981

[5] MR Green, The impact of social networks in the development of a personal sports brand. Sport, Business and Management, 2016,6, 274-294

[6] S Vallor, Flourishing on facebook: virtue friendship \& new social media, Ethics and Information Technology, 2012, 14(3):1-15

[7] SL Mcgaughey,PW Liesch, The Global Sports\&ndash;Media Nexus: Reflections on the \&lsquo;Super League Saga\&rsquo; in Australia, Journal of Management Studies, 2002, 39(3):383-416

[8] J Vlaanderen,LE Moore,MT Smith,Q Lan,L Zhang,. Application of OMICS technologies in occupational and environmental health research; current status and projections.[J]. OEM Online, 2010, 67(2):136

[9] B Zheng,W Wang,G Jiang,K Wang,X Mei, Research status and application prospects of manufacturing technology for micro-nano surface structures with low reflectivity[J]. Proceedings of the Institution of Mechanical Engineers, 2014, 229(11):953-965

[10]P Korzynski,J Paniagua, Score a tweet and post a goal: Social media recipes for sports stars[J]. Business Horizons, 2016, 59(2):185-192 